\title{
In vitro Antibacterial, Antifungal and Phytochemical Analysis of Methanolic Extract of Fruit Cassia fistula
}

\author{
MOHANAD JAWAD KADHIM', GHAIDAA JIHADI MOHAMMED² \\ and IMAD HADI HAMEED ${ }^{3 *}$ \\ 'Department of Genetic Engineering,, Al-Qasim Green University, Iraq. \\ ${ }^{2}$ College of Science, Al-Qadisyia University, Iraq. \\ ${ }^{3}$ College of Nursing, Babylon University, Iraq. \\ ${ }^{*}$ Corresponding author E-mail: imad_dna@yahoo.com \\ http://dx.doi.org/10.13005/ojc/320307
}

(Received: April 02, 2016; Accepted: May 05, 2016)

\begin{abstract}
The identification of phytochemical compounds is based on the peak area, retention time molecular weight, molecular formula, MS Fragment- ions and Pharmacological actions. GCMS analysis of Cassia fistula revealed the presence of the Oxacyclododecan-2-one, Imidazole ,2-amino-5-[(2-carboxy)vinyl], D-Glucose , 6-O-á-D-galactopyranosyl, 2-Nonanone, Eicosanoic acid, phenylmethyl ester, Phenol , 4-(2-propenyl), Eugenol, Caryophyllene, ß-copaene, Azulene,1,2,3,3a,4,5,6,7-octahydro-1,4-dimethyl-7-(1-methylethenyl), á-acorenol, Spiro[5.5] undec-8-en-1-one, Isoaromadendrene epoxide, Tetraacetyl-d-xylonic nitrile , Benzyl Benzoate, $\mathrm{N}$-Isobutyl-(2E,4Z,8Z,10E)-dodecatetraenamide, Phenethylamine , 3-benzyloxy-2-fluoro-ß-hydroxy, 4a-Hydroxy-4-nitroperhydronaphthalen-1-one, Dasycarpidan -1-methanol, acetate (ester), Propanoic acid , 2-(3-acetoxy-4,4,14-trimethylandrost-8-en-17-yl), Carda-4,20(22)-dienolide,3-[(6-deoxy-3-Omethyl-á-L-mannopyranosyl, Cis-13-Eicosenoic acid , 16-Nitrobicyclo[10.4.0]hexadecane-1-ol-13one, Strychane ,1-acetyl-20á-hydroxy-16-methylene, 2,4,6-Decatrienoic acid , 1a,2,5,5a,6,9,10,10aoctahydro-5,5a-dihydro, Vitamin E and Glycine ,N-[(3á,5ß,12á)-3,12-dihydroxy-24-oxocholan-24$\mathrm{yl}$. The FTIR analysis of Cassia fistula leaves proved the presence of Alkenes, Aliphatic fluoro compounds, Alcohols, Ethers, Carboxlic acids, Esters, Nitro Compounds, Alkanes, Alcohols and Phenol. Cassia fistula was highly active against Aspergillus terreus (6.99 \pm 0.29$)$. Methanolic extract of bioactive compounds of Cassia fistula was assayed for in vitro antibacterial activity against eleven pathogenic bacteria by using the diffusion method in agar. The zone of inhibition were compared with different standard antibiotics. The diameters of inhibition zones ranged from $1.00 \pm 0.05$ to $6.02 \pm 0.23$ $\mathrm{mm}$ for all treatments.
\end{abstract}

Keywords: GC/MS, Bioactive compounds, FT-IR, Cassia fistula.

\section{INTRODUCTION}

Cassia fistula plant have naturally occurring bioactive compounds and are mostly secondary metabolites which are now a days being used as medicines, dietary supplements and other useful commercial products ${ }^{1}$. Also, has been reported to contain anthraquinone the principal laxative constituent of many plants used as purgative ${ }^{2}$. Plants have been an important source of medicine 
with qualities for thousands of years ${ }^{3,4}$. Mainly on traditional remedies such as herbs for their history, they have been used as popular folk medicines ${ }^{5,6}$. Since thousands of years back, plants are used as a major source for medicine as they found to possess a reservoir of bioactive compound ${ }^{7-9}$. Cassia fistula contains alkaloids, tannins, flavonoids,terpenes, sugars, and glucosides. Tannins are naturally occurring and water soluble phenolic compounds, which precipitate proteins from aqueous media ${ }^{10}$. Cassia fistula shows the presence of glycoside a natural product, which is used to enhance the cardiac contractile force in patient with congestive heart failure ${ }^{11}$ glycoside also plays major role in the cancer therapy ${ }^{12}$. They also play major role in controlling topical disease as eczema etc. Many metabolites have found to possess interesting biological activities such as bactericidal, fungicidal, hepatoprotective and muscle relaxant ${ }^{13}$. A fruit is cylindrical pod and seeds many in black, sweet pulp separated by transverse partitions. The long pods which are green, when unripe, turn black on ripening after flowers shed ${ }^{14}$. Pulp is dark brown in colour, sticky, sweet and mucilaginous, odour characteristic, and somewhat disagreeable ${ }^{15}$. Each compartment contains one seed which is flat, oval, reddish brown with a well-marked raphe. The seed contains a whitish endosperm in which the yellowish embryo is embedded ${ }^{16}$. Fruits are used in the treatment of diabetes, antipyretic, abortifacient, demulcent, lessens inflammation and heat of the body; useful in chest complaints, throat troubles, liver complaints, diseases of eye and gripping ${ }^{17}$. The aim of this research was study the phytochemical composition of Cassia fistula and to evaluate the isolates for possible in vitro antifungal and antibacterial activities.

\section{MATERIALS AND METHODS}

\section{Solvent extraction}

The shade dried powdered of Cassia fistula was extracted with methanol. The extract was filtered with Whatman's filter paper. Filtrate was concentrated under reduced pressure and preserved at $5 C^{\circ}$ in dark air tight bottles ${ }^{18,19}$.

\section{Sample preparation for GC-MS analysis}

$50 \mu$ of sample (Cassia fistula) was dissolved in $2 \mathrm{ml}$ of methanol and kept in ultrasonic bath for $25 \mathrm{~min}$ and centrifuged for $10 \mathrm{~min}$. at 6000 rpm and supernatant was injected in GC-MS for analysis ${ }^{20,21}$.

\section{Gas chromatography-mass spectrometry (GC- MS) analysis}

GC-MS of methanol extract was performed using Agilent 7890A. The run time was 30 minutes. ionization of sample components were performed on El mode (70 eV). The carrier gas was helium at $1.0 \mathrm{ml} / \mathrm{min}$ flow rate. $0.5 \mathrm{ml}$ of sample was injected in split mode of 20:1.The mass spectrum scan range was set at 29.0 to $500(\mathrm{~m} / \mathrm{z})^{22}$.

\section{Identification of compounds}

Interpretation of mass spectrum of GCMS was done using the database of National Institute Standard and Technology (NIST). The mass spectrum of phytochemicals was compared with the spectrum of known compounds stored in the NIST library ${ }^{23}$.

\section{Determination of antibacterial activity of crude bioactive compounds of Cassia fistula}

The anti-bacterial activity was evaluated using Mueller-Hinton agar. The bacterial plates were incubated at $37^{\circ} \mathrm{C}$ for $24 \mathrm{~h}$. After incubation, the diameter of the inhibition zone was measured to evaluate the antimicrobial activity. Each test was performed twice and the average of the results was calculated. The extraction solvents were used as negative control ${ }^{24,25}$. The test pathogens were swabbed in Muller Hinton agar plates. 60il of plant extract was loaded on the bored wells. The wells were bored in $0.5 \mathrm{~cm}$ in diameter. The plates were incubated at $37 \mathrm{C}^{\circ}$ for $24 \mathrm{~h}$ and examined. After the incubation the diameter of inhibition zones around the discs was measured ${ }^{26}$.

\section{Determination of antifungal activity}

Five-millimeter diameter wells were cut from the agar using a sterile cork-borer, and 50 il of the samples solutions Cassia fistula was delivered into the wells. Antimicrobial activity was evaluated by measuring the zone of inhibition against the test microorganisms. Methanol was used as solvent control. Amphotericin B and fluconazole were used as reference antifungal agent. The tests were carried out in triplicate. The antifungal activity was evaluated by measuring the inhibition-zone diameter observed after $48 \mathrm{~h}$ of incubation ${ }^{27,28}$. 


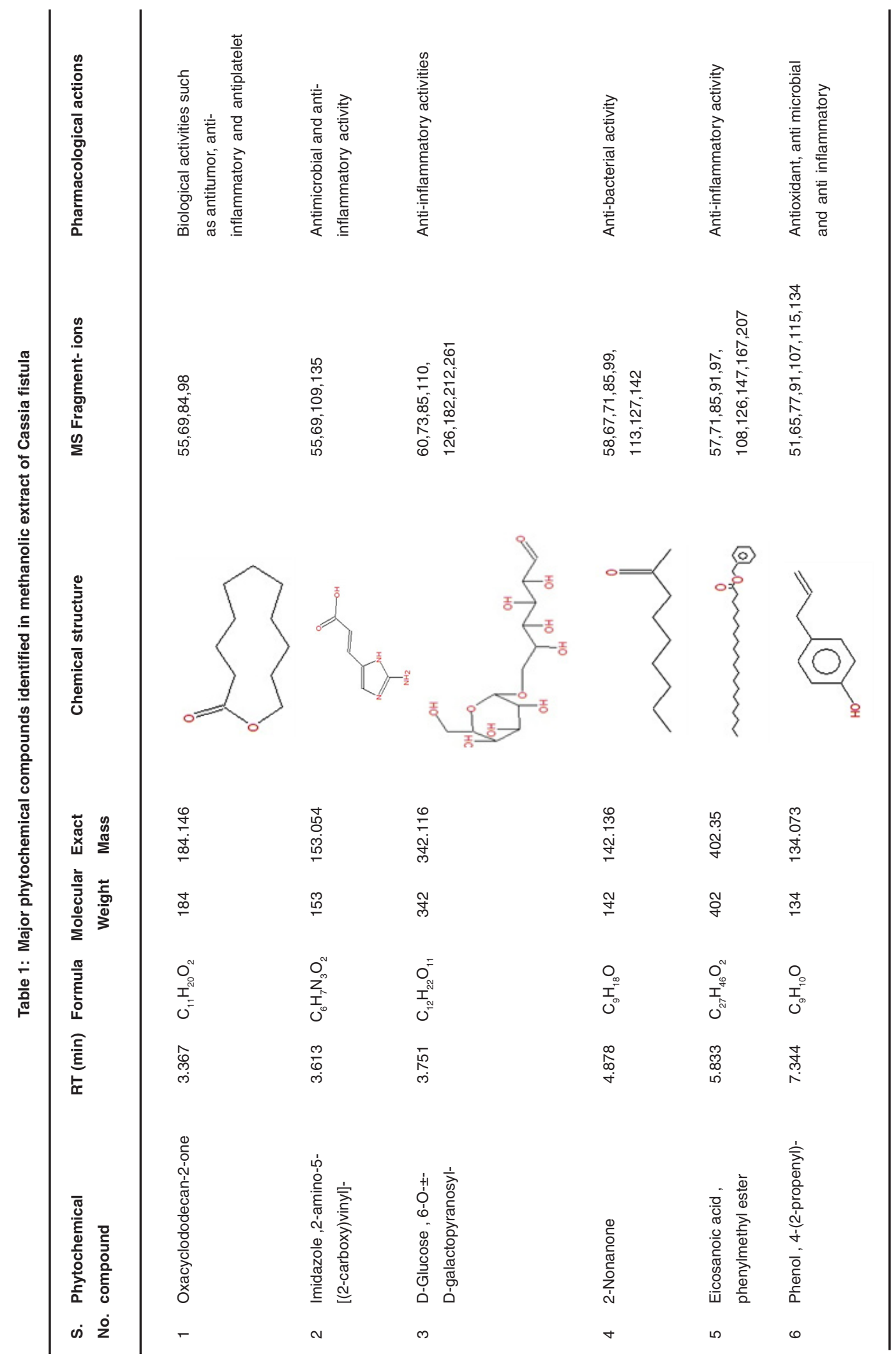




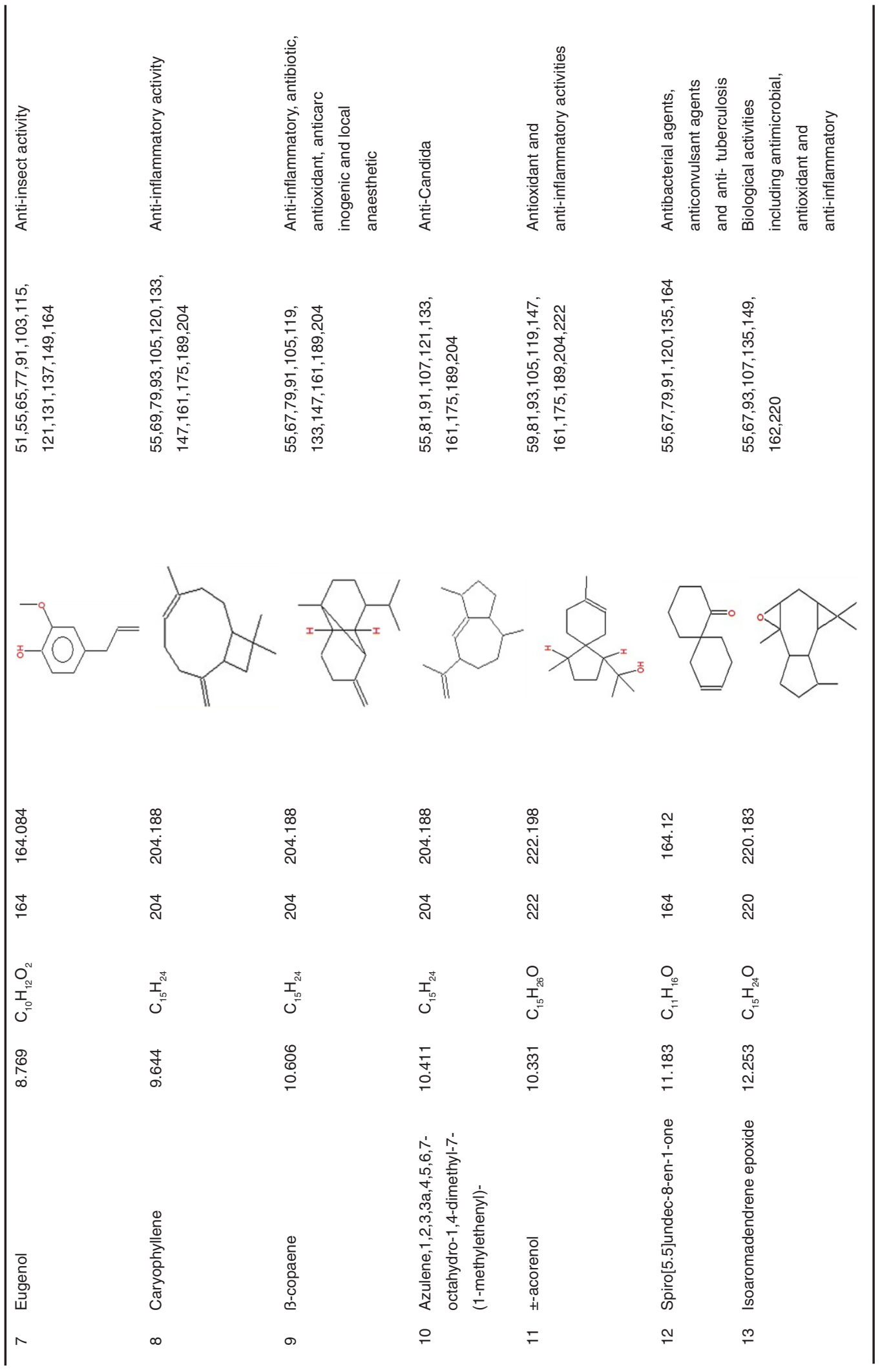




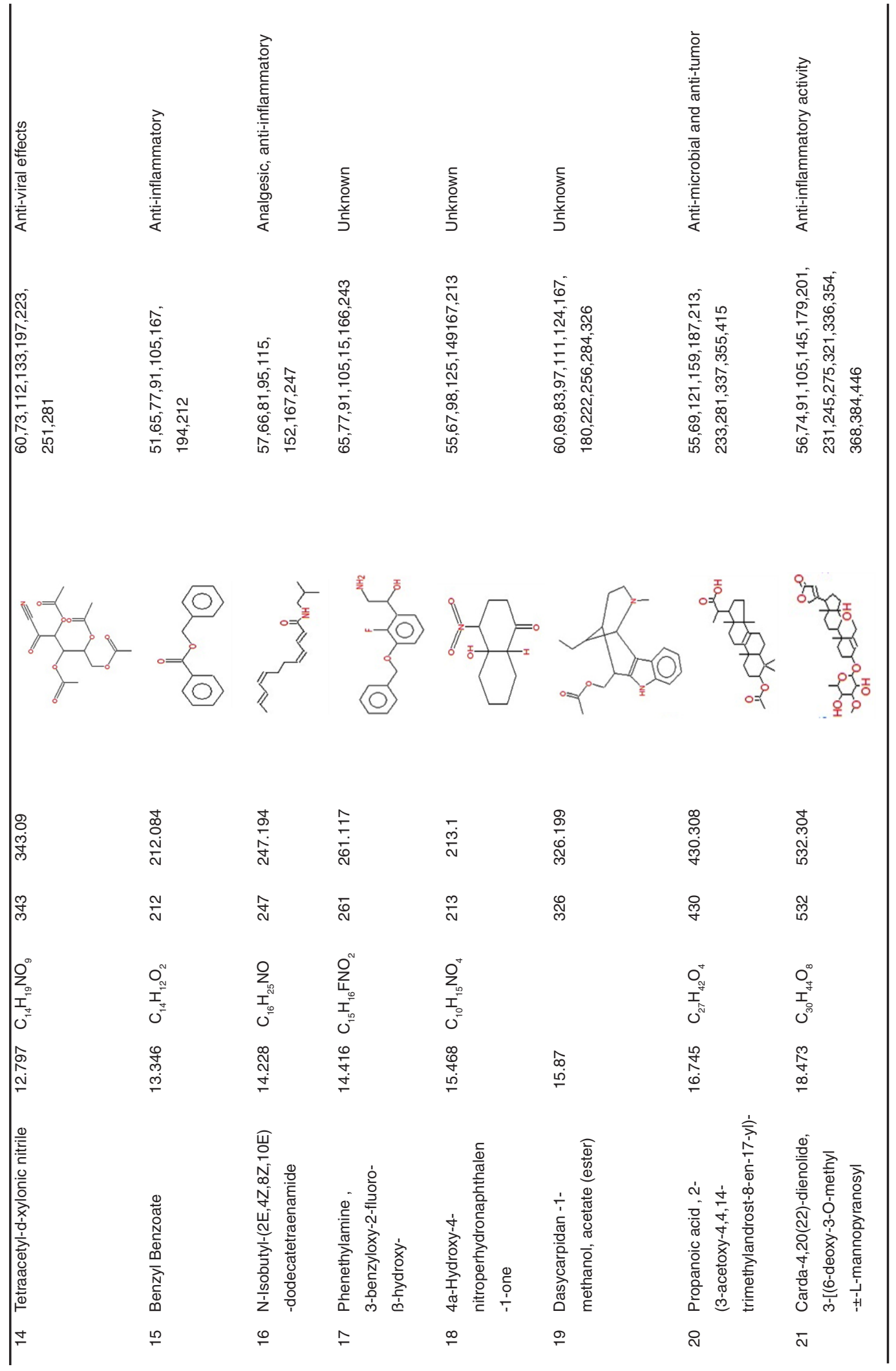




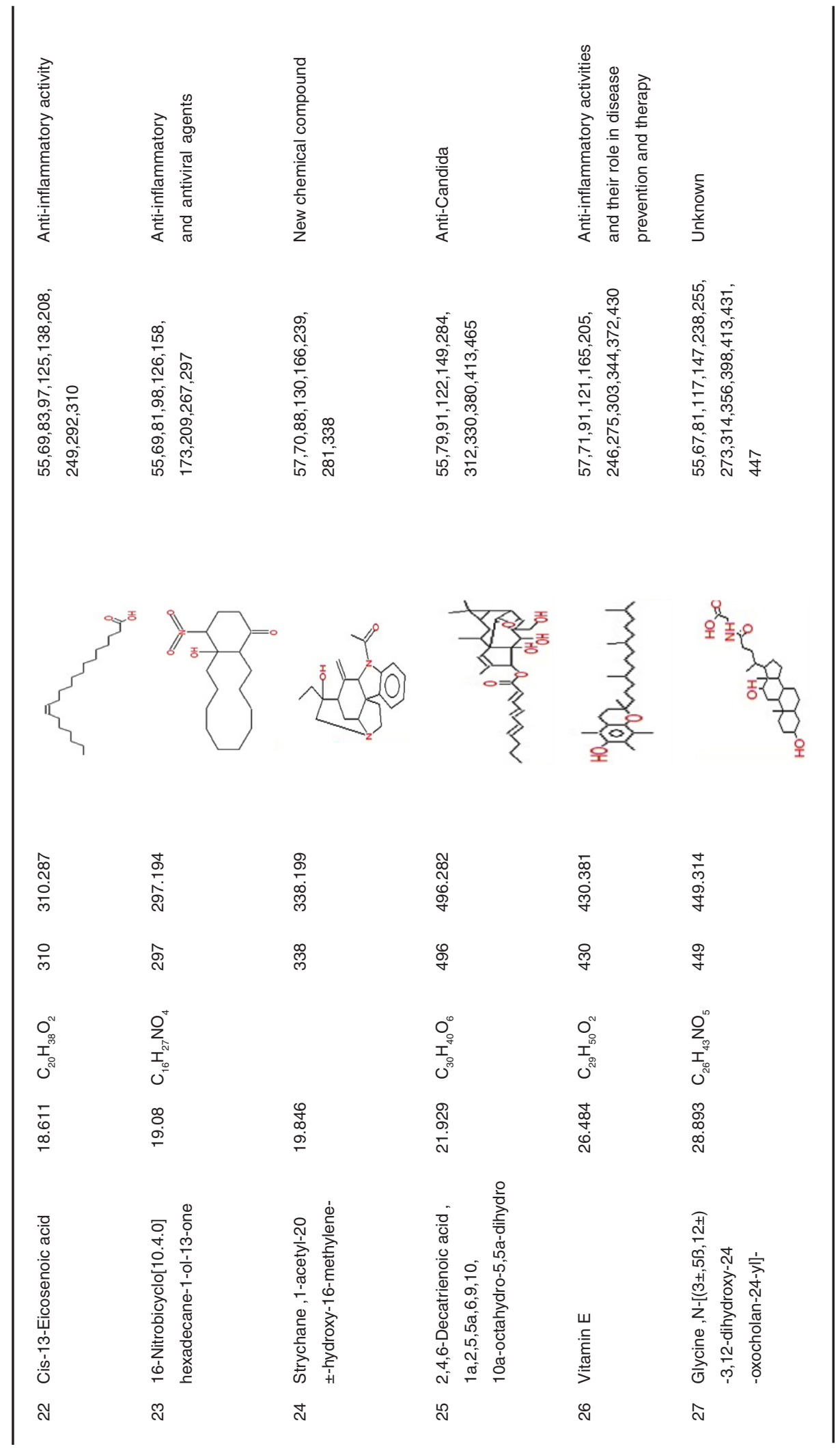


Statistical analysis

Results of the study were based on analysis of variance (ANOVA) and differences were considered significant at $p<0.05$.

\section{RESULTS AND DISCUSSION}

Identification of phytochemical compounds

Plants have been a common source of medicinal property, either in the form of pure active

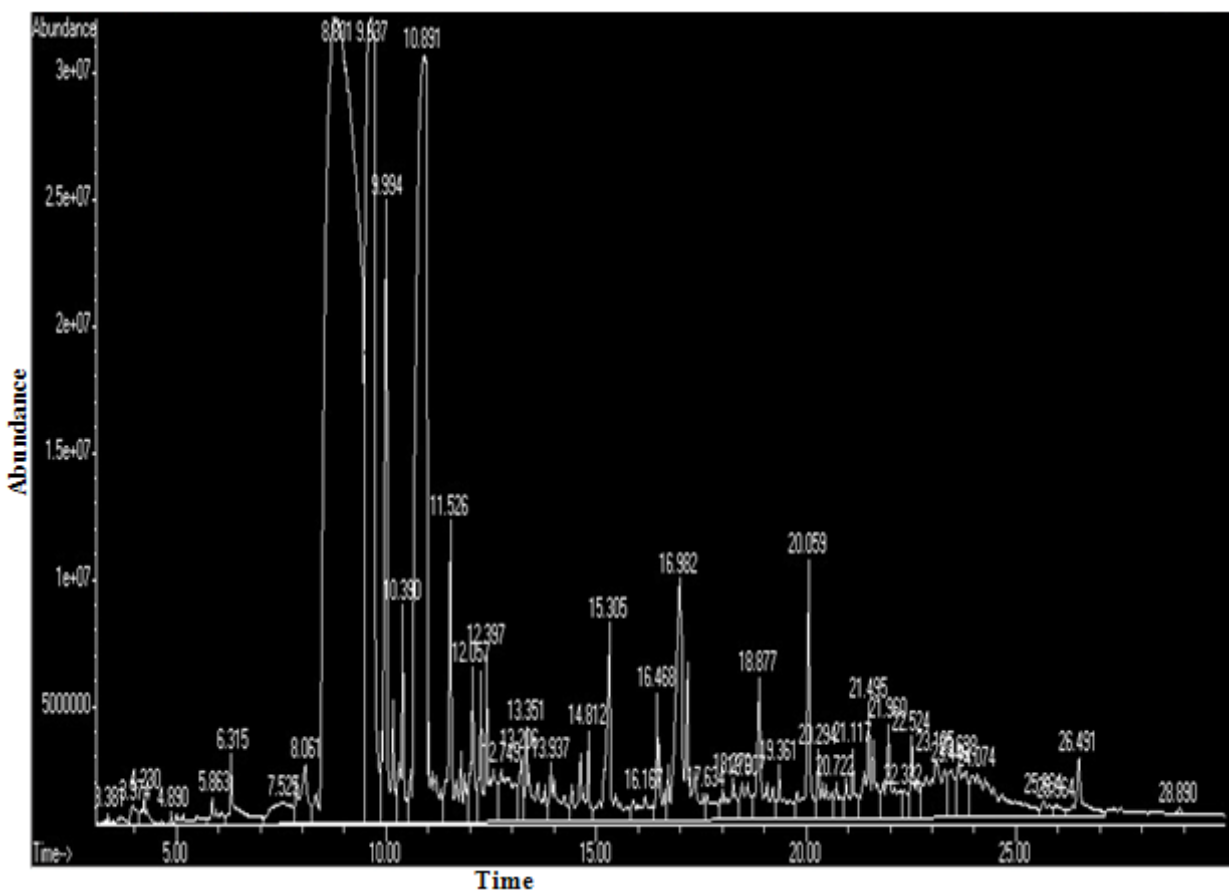

Fig. 1: GC-MS chromatogram of Cassia fistula

Table 2: FT-IR peak values of Cassia fistula

\begin{tabular}{llllll}
\hline No. & $\begin{array}{l}\text { Peak (Wave } \\
\text { number cm-1) }\end{array}$ & Intensity & Bond & $\begin{array}{l}\text { Functional group } \\
\text { assignment }\end{array}$ & $\begin{array}{l}\text { Group } \\
\text { frequency }\end{array}$ \\
\hline 1 & 675.09 & 57.314 & C-H & Alkenes & $675-995$ \\
2 & 904.61 & 72.826 & C-H & Alkenes & $675-995$ \\
3 & 921.97 & 72.347 & C-H & Alkenes & $675-995$ \\
4 & 1014.56 & 51.417 & C-F stretch & Aliphatic fluoro compounds & $1000-10150$ \\
5 & 1072.42 & 57.43 & C-F stretch & Aliphatic fluoro compounds & $1000-10150$ \\
6 & 1242.16 & 72.837 & C-O & Alcohols, Ethers, Carboxlic acids, Esters & $1050-1300$ \\
7 & 1317.38 & 74.466 & NO2 & Nitro Compounds & $1300-1370$ \\
8 & 1361.74 & 72.514 & NO2 & Nitro Compounds & $1300-1370$ \\
9 & 1373.32 & 72.15 & - & Unknown & - \\
10 & 1595.13 & 69.134 & - & Unknown & - \\
11 & 1732.08 & 83760 & - & Unknown & - \\
12 & 2752.42 & 90.502 & - & Unknown & - \\
13 & 2848.86 & 77.274 & - & Unknown & - \\
14 & 2918.3 & 72.553 & C-H & Alkanes & $2850-2970$ \\
15 & 3277.06 & 76.261 & O-H & Hydrogen bonded Alcohols, Phenols & $3200-3600$ \\
\hline
\end{tabular}


compound or as traditional preparations and it are reasonable to use local plants ${ }^{29}$. Identifying on the plant phytochemistry provides a fundamental use of plants as storage of chemical agents in the field of medicine ${ }^{13}$. The phytochemical analyses of plant from Cassia fistula was studied extensively. Identifying the importance of secondary metabolites in the field of medicine, the presence of tannins, phlobatanins, saponins, flavonoids, terpenoids, glycosides and steroids was detected. Folklore medicine are widely used in our ancient period ${ }^{13}$. Gas chromatography and mass spectroscopy analysis of compounds was carried out in methanolic leaves extract of Cassia fistula, shown in Table 1. The GC-MS chromatogram of the 27 peaks of the compounds detected was shown in Figure 1. Chromatogram GC-MS analysis of the methanol extract of Cassia fistula showed the presence of twenty seven major peaks and the components corresponding to the peaks were determined as follows. The first set up peak were determined to be 1,7-Dioxaspiro[5,5] undec-2-ene Figure 2. The second peak indicated to be 2,4-Dihydroxy-2,5-dimethyl-39(2H)-furan-3one Figure 3. The next peaks considered to be á-D-Glucopyranoside , O-á-D-glucopyranosyl-(1. fwdarw.3)-B-D-fruc, d-Mannose, 5,7-Dodecadiyn -1,12-diol, 3-Trifluoroacetoxypentadecane, 3-Trifluoroacetoxypentadecane, Pterin-6-carboxylic acid, Imidazole-4-carboxylic acid ,2-fluoro-1methoxymethyl-,ethyl ester, D-Carvone, Pyrrolizin-

Table 3: Antimicrobial activity of Cassia fistula

Microbe $\quad$ Plant Cefotoxime Streptomycin Amphotericin B Fluconazol

\begin{tabular}{llll}
\hline Streptococcus pneumonia & $4.19 \pm 0.15$ & $1.00 \pm 0.07$ & $2.00 \pm 0.11$ \\
Pseudomonas eurogenosa & $5.73 \pm 0.20$ & $1.30 \pm 0.09$ & $1.07 \pm 0.06$ \\
Staphylococcus epidermidis & $3.00 \pm 0.10$ & $1.31 \pm 0.09$ & $1.56 \pm 0.09$ \\
Salmonella typhi & $4.15 \pm 0.14$ & $1.01 \pm 0.08$ & $1.22 \pm 0.08$ \\
Bacillus subtilis & $4.00 \pm 0.12$ & $1.49 \pm 0.10$ & $1.00 \pm 0.04$ \\
Escherichia coli & $4.83 \pm 0.19$ & $2.03 \pm 0.11$ & $2.08 \pm 0.10$ \\
Proteus mirabilis & $6.02 \pm 0.23$ & $1.90 \pm 0.09$ & $1.00 \pm 0.05$ \\
Streptococcus pyogenes & $3.04 \pm 0.11$ & $1.16 \pm 0.09$ & $1.82 \pm 0.05$ \\
Staphylococcus aureus & $5.20 \pm 0.20$ & $2.00 \pm 0.10$ & $2.11 \pm 0.12$ \\
Streptococcus faecalis & $4.65 \pm 0.20$ & $1.58 \pm 0.08$ & $1.00 \pm 0.05$ \\
Klebsiella pneumonia & $5.23 \pm 0.23$ & $1.27 \pm 0.07$ & $1.95 \pm 0.09$
\end{tabular}

Fungi/ Yeast

Aspergillus niger

Aspergillus terreus

Aspergillus flavus

Aspergillus fumigatus

Candida albicans

Saccharomyces cerevisiae

Fusarium sp.

Microsporum canis

Streptococcus faecalis

Mucor sp.

Penicillium expansum

Trichoderma viride

$\begin{array}{ll}5.89 \pm 0.22 & - \\ 6.99 \pm 0.29 & - \\ 5.96 \pm 0.28 & - \\ 6.00 \pm 0.29 & - \\ 5.25 \pm 0.20 & - \\ 3.92 \pm 0.18 & - \\ 5.01 \pm 0.24 & - \\ 4.00 \pm 0.19 & - \\ 3.80 \pm 0.27 & - \\ 4.00 \pm 0.19 & - \\ 4.12 \pm 0.19 & - \\ 5.08 \pm 0.23 & \\ 3.95 \pm 0.17 & \\ 4.00 \pm 0.19 & \end{array}$

$\begin{array}{lll}- & 1.94 \pm 0.08 & 2.11 \pm 0.19 \\ - & 4.00 \pm 0.16 & 1.95 \pm 0.18 \\ - & 2.00 \pm 0.20 & 3.00 \pm 0.22 \\ - & 2.06 \pm 0.09 & 2.85 \pm 0.17 \\ - & 2.00 \pm 0.19 & 2.00 \pm 0.11 \\ - & 1.89 \pm 0.09 & 2.90 \pm 0.19 \\ - & 2.99 \pm 0.10 & 3.00 \pm 0.21 \\ - & 3.31 \pm 0.19 & 1.97 \pm 0.10 \\ - & 3.73 \pm 0.14 & 2.60 \pm 0.20 \\ - & 2.00 \pm 0.17 & 1.99 \pm 0.18 \\ - & 2.61 \pm 0.19 & 2.60 \pm 0.17 \\ & 1.99 \pm 0.15 & 2.30 \pm 0.18 \\ & 0.94 \pm 0.01 & 2.99 \pm 0.19 \\ & 2.71 \pm 0.14 & 1.00 \pm 0.14\end{array}$

Trichophyton mentagrophytes $\quad 4.00 \pm 0.19$

a The values (average of triplicate) are diameter of zone of inhibition at $100 \mathrm{mg} / \mathrm{mL}$ crude extract, $30 \mu \mathrm{g} / \mathrm{mL}$ of antibiotics (Streptomycin; Rifambin; Kanamycin; Cefotoxime and chloramphenicol). 


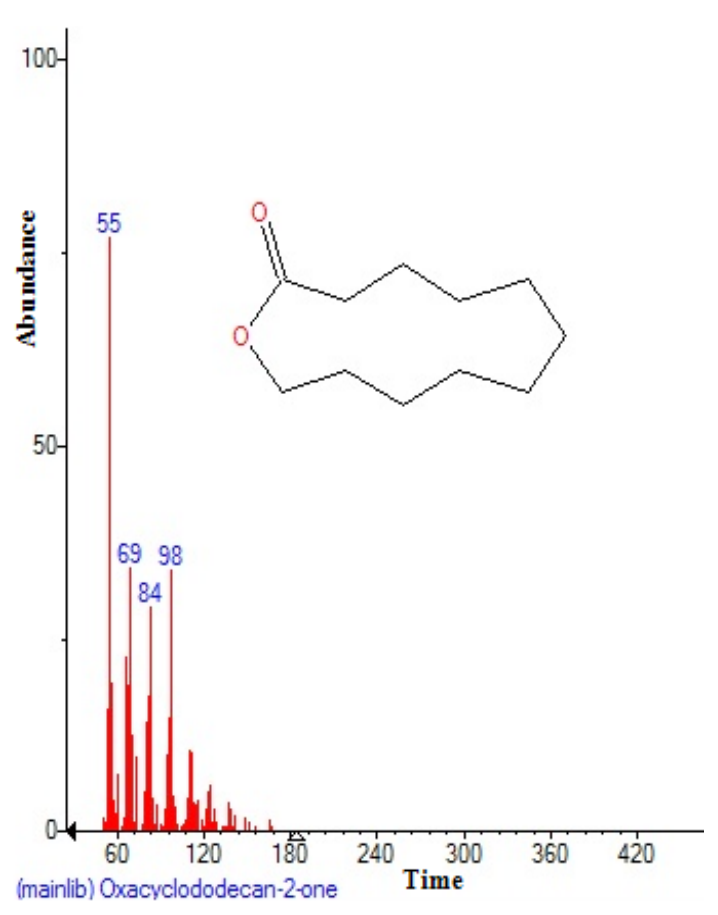

Fig. 2: Structure of Oxacyclododecan-2-one with RT: 3.367 present in Cassia fistula

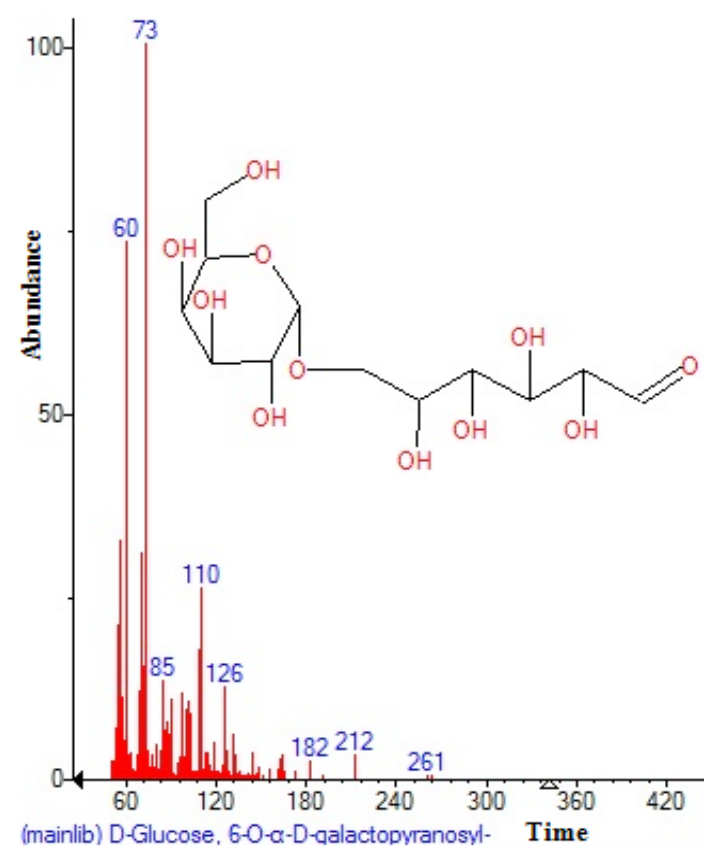

Fig. 4: Structure of D-Glucose , 6-O- $\alpha-D-$ galactopyranosyl with RT: 3.751 present in Cassia fistula

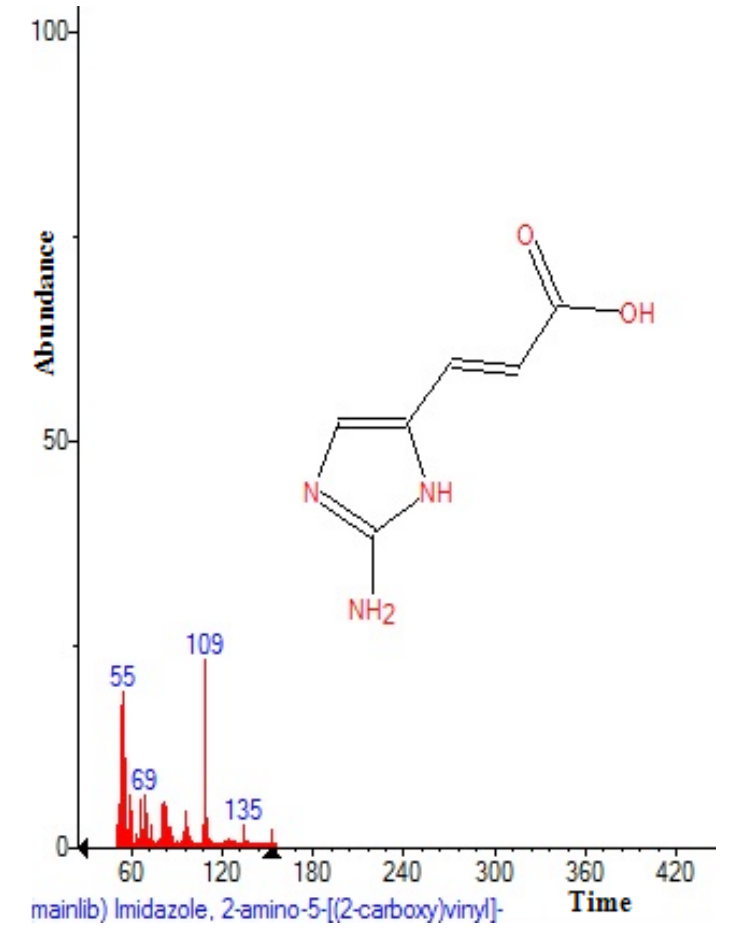

Fig. 3: Structure of Imidazole ,2-amino-5[(2-carboxy)vinyl] with RT: 3.613 present in Cassia fistula

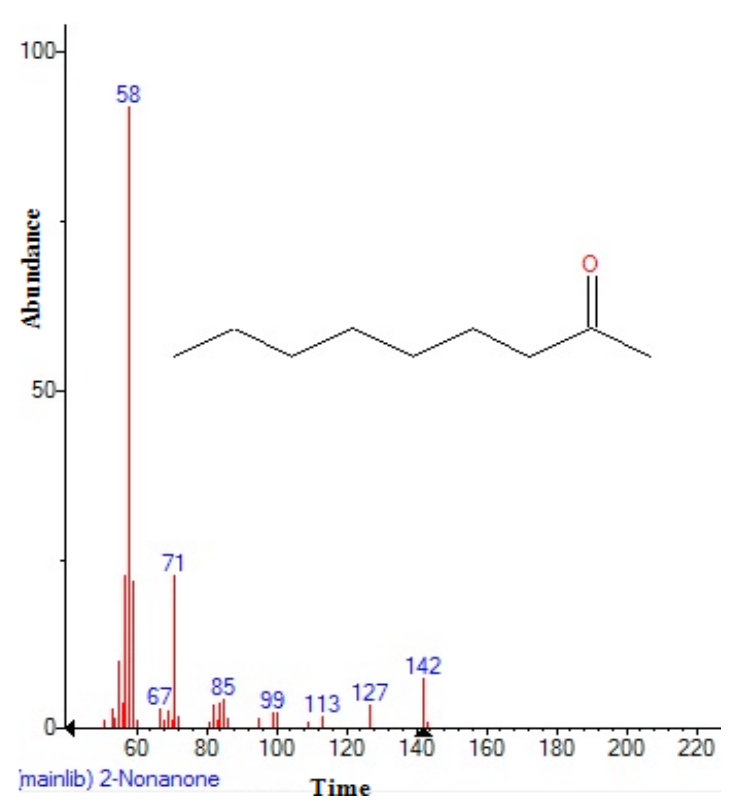

Fig. 5: Structure of 2-Nonanone with RT: 4.878 present in Cassia fistula 


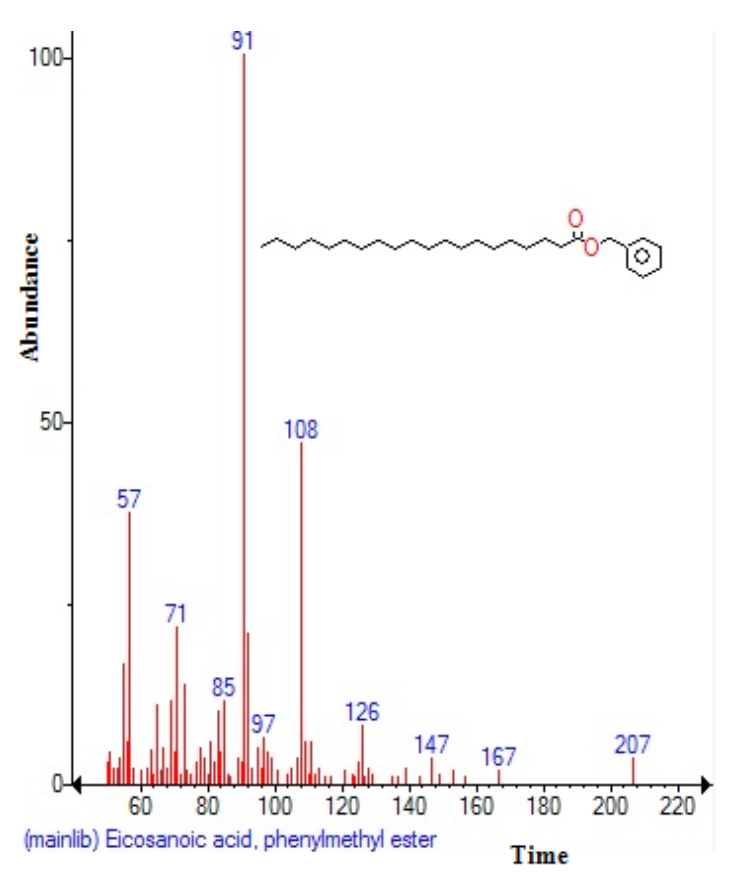

Fig. 6: Structure of Eicosanoic acid, phenylmethyl ester with RT: $\mathbf{5 . 8 3 3}$ present in Cassia fistula

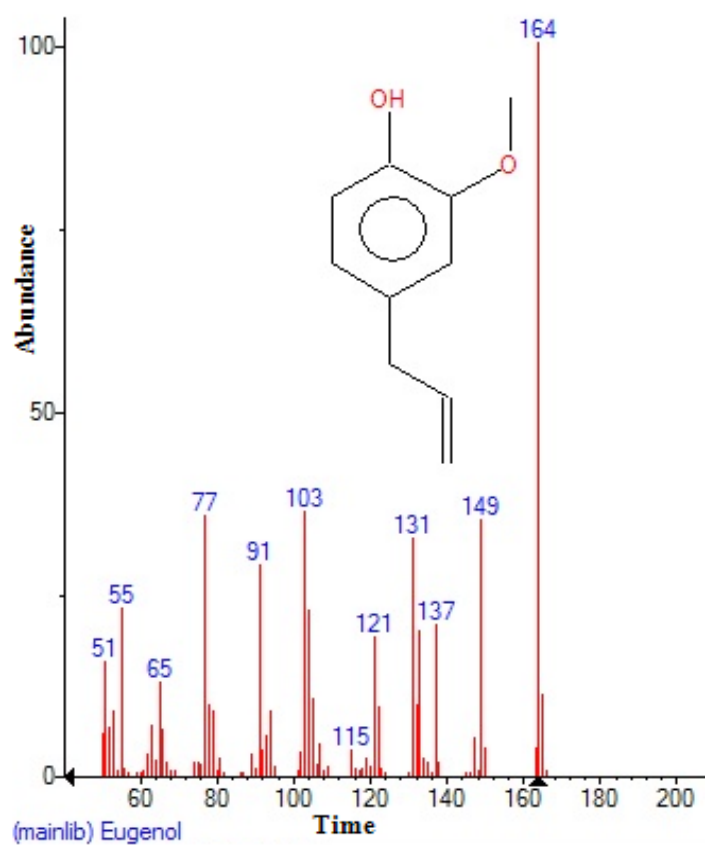

Fig. 8: Structure of Eugenol with RT: 8.769 present in Cassia fistula

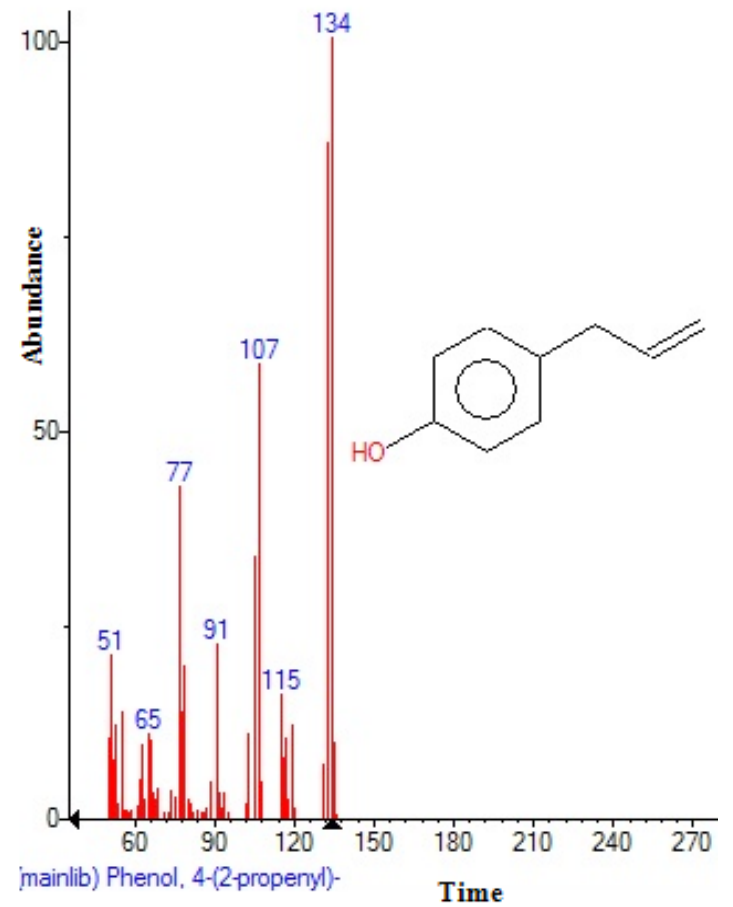

Fig. 7: Structure of Phenol, 4-(2-propenyl) with RT: 7.344 present in Cassia fistula

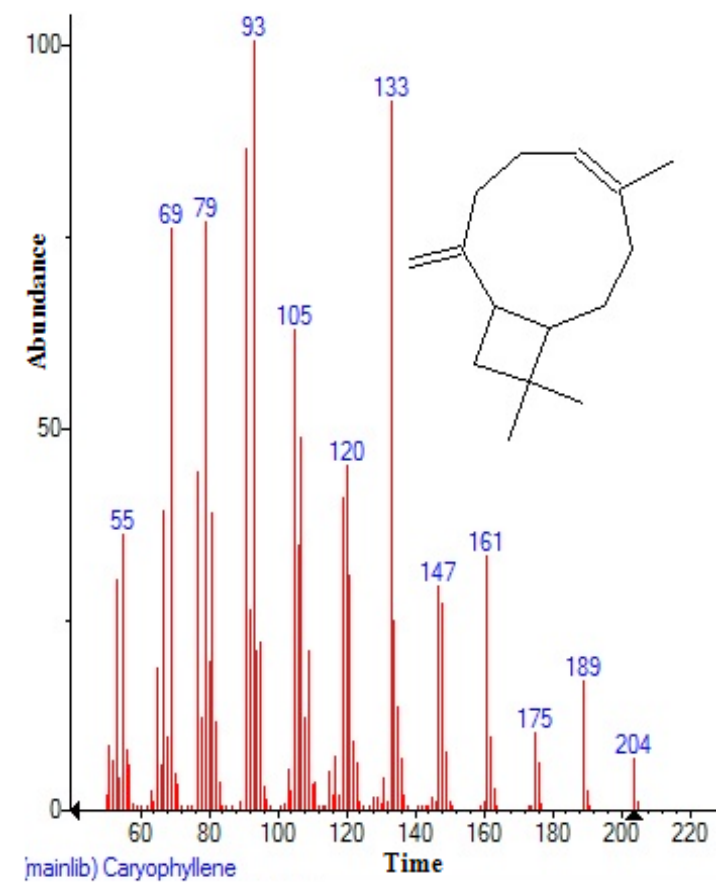

Fig. 9: Structure of Caryophyllene with RT: 9.644 present in Cassia fistula 


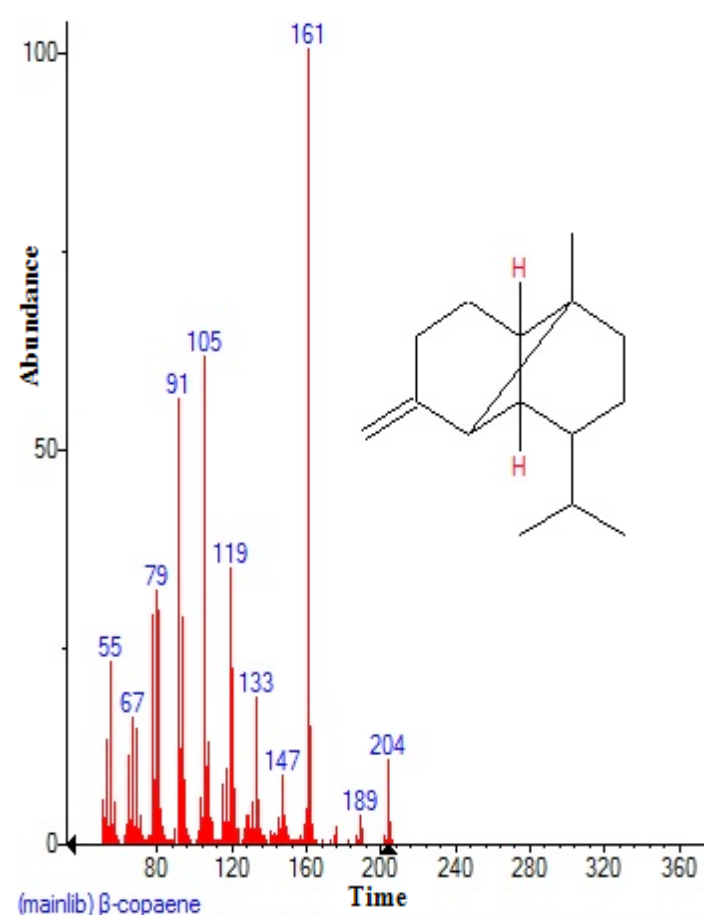

Fig. 10: Structure of B-copaene with RT: 10.606 present in Cassia fistula

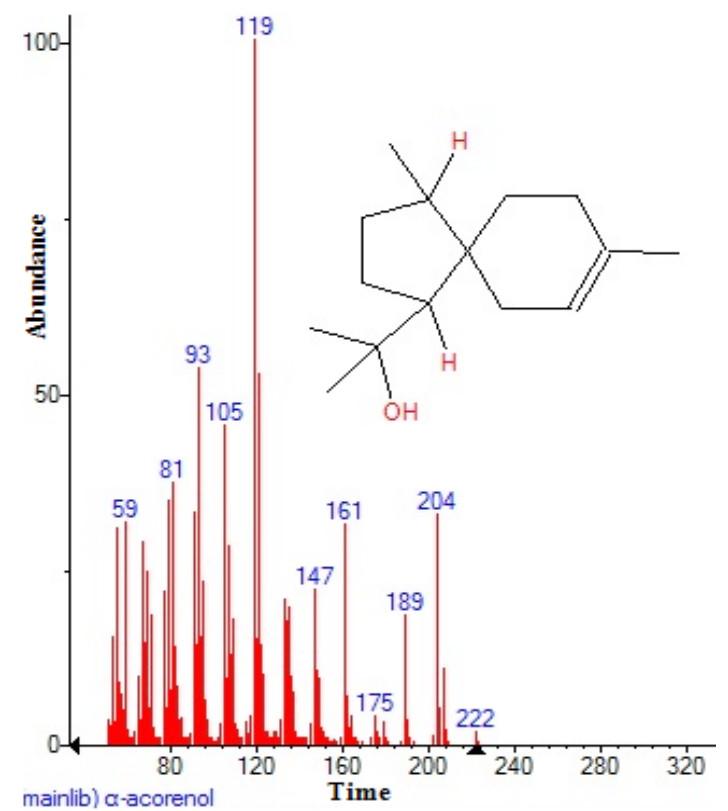

Fig. 12: Structure of á-acorenol with RT: 10.331 present in Cassia fistula

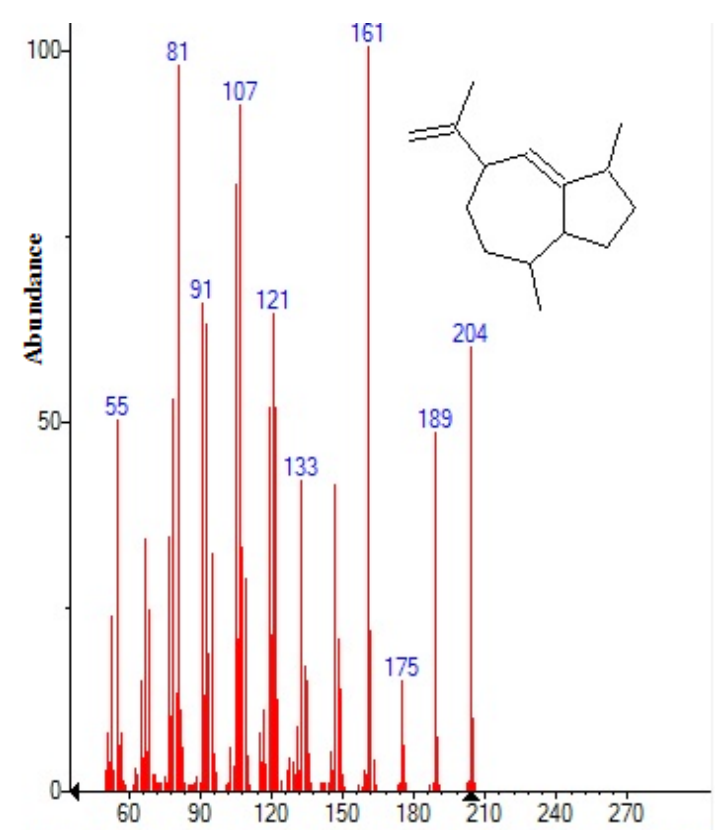

(mainlib) Azulene, 1,2,3,3a,4,5,6,7-octahydro-1,4-dimethyl-7-(1-methylethen Time

Fig. 11: Structure of Azulene,1,2,3,3a,4,5,6,7octahydro-1,4-dimethyl-7-(1-methylethenyl) with RT: 10.411 present in Cassia fistula

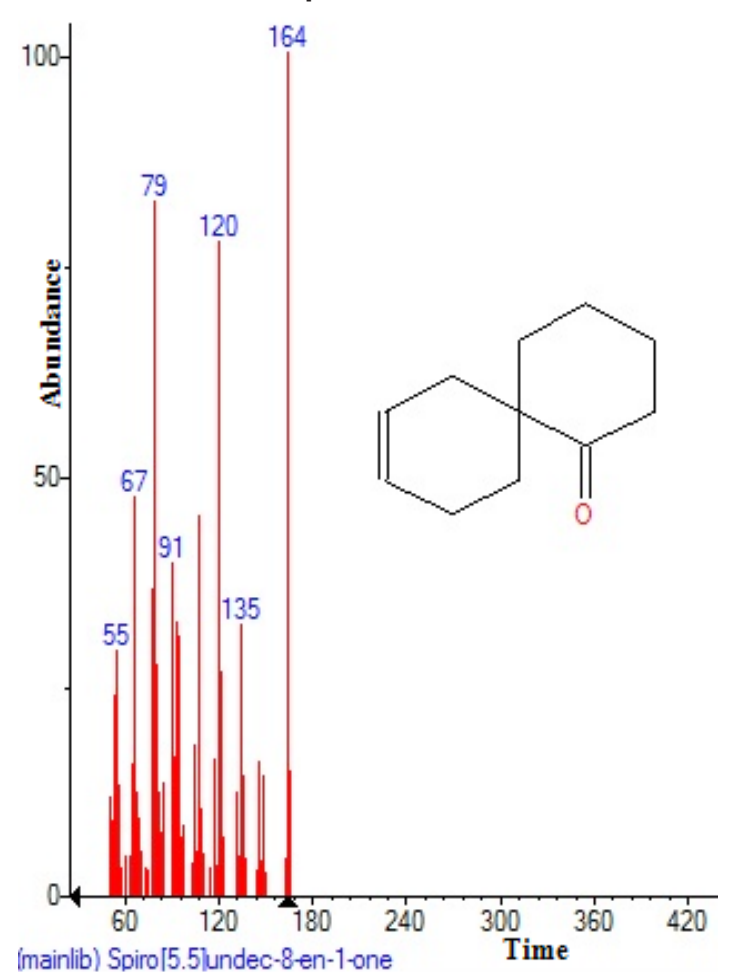

Fig. 13: Structure of Spiro[5.5]undec-8-en-1one with RT: 11.183 present in Cassia fistula 


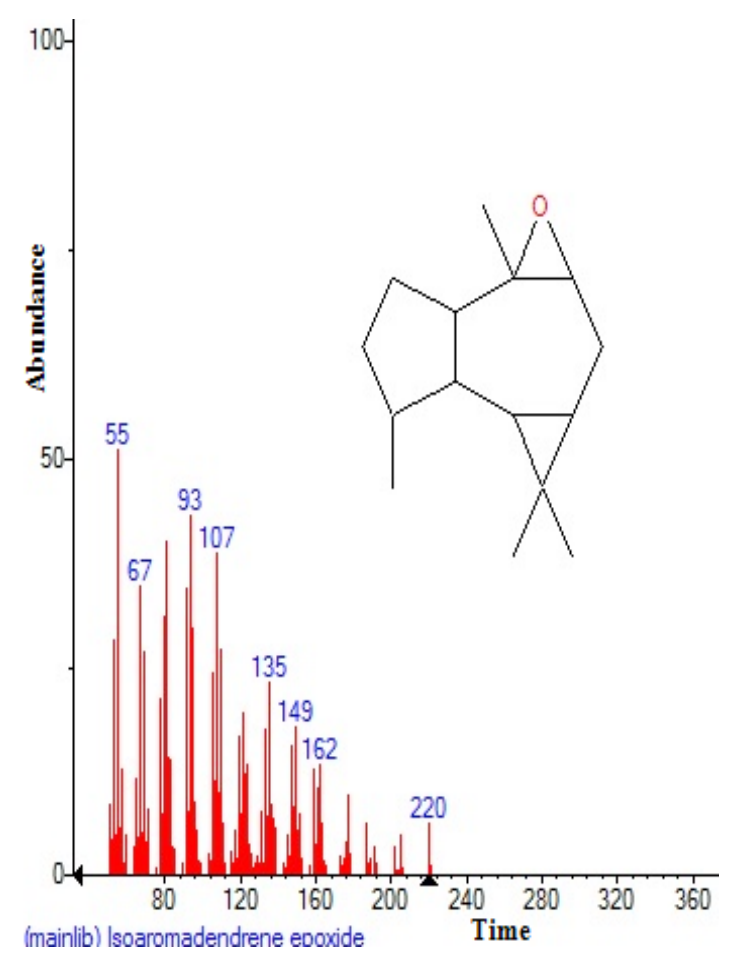

Fig. 14: Structure of Isoaromadendrene epoxide with RT: 12.253 present in Cassia fistula

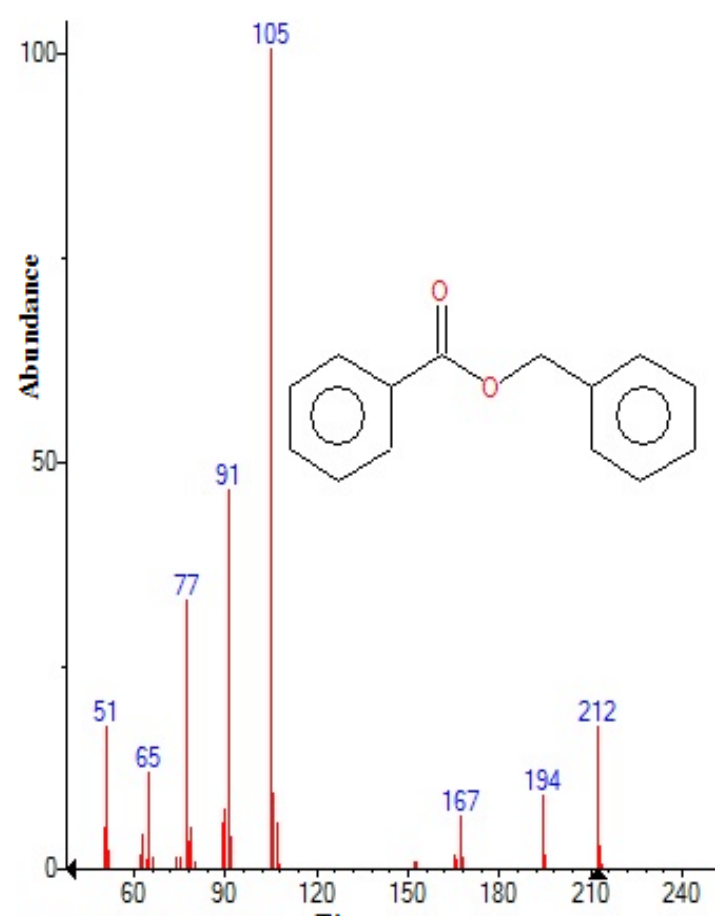

(mainlib) Benzyl Benzoate Time

Fig. 16: Structure of Benzyl Benzoate with RT: 13.346 present in Cassia fistula

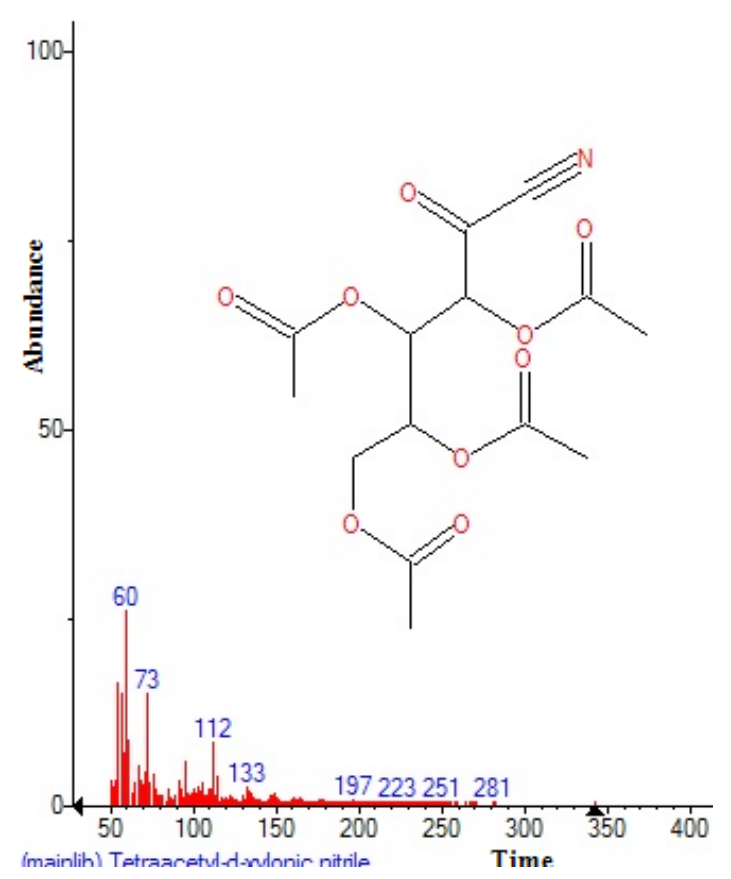

Fig. 15: Structure of Tetraacetyl-d-xylonic nitrile with RT: 12.797 present in Cassia fistula

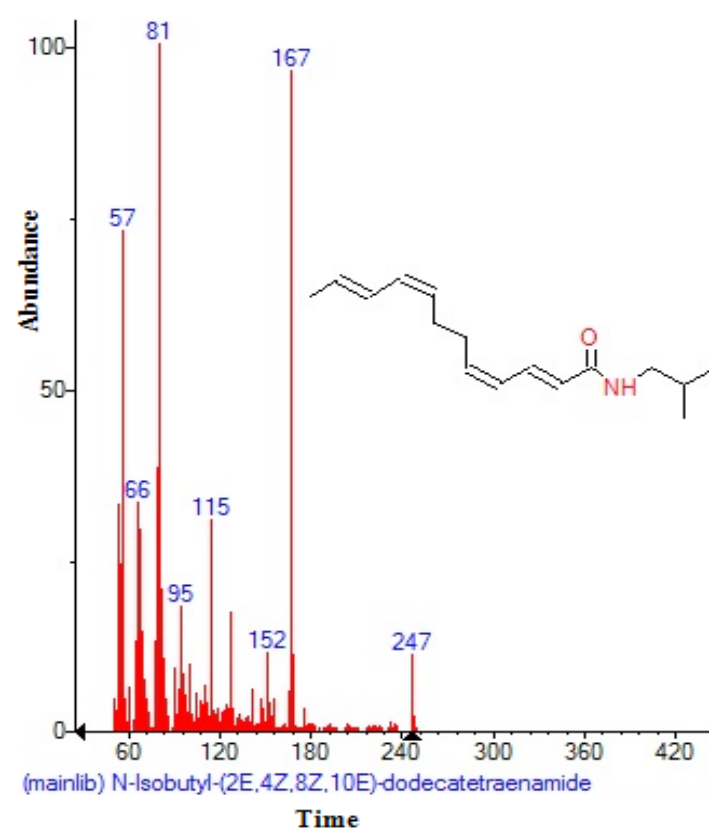

Fig. 17: Structure of N-Isobutyl-(2E,4Z,8Z,10E)dodecatetraenamide with RT: 14.228 present in Cassia fistula 


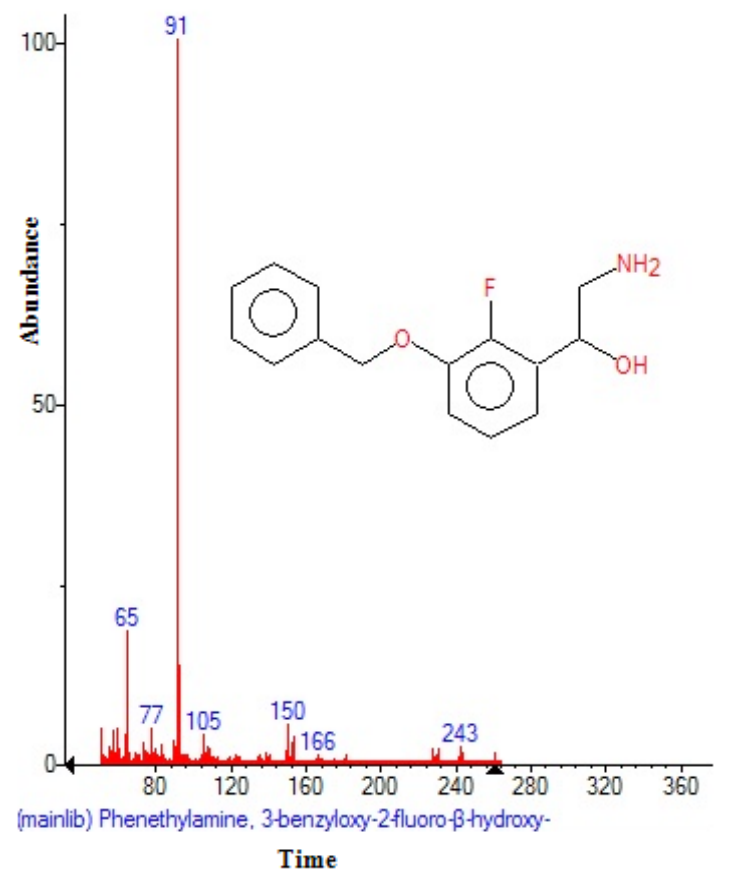

Fig. 18: Structure of Phenethylamine, 3-benzyloxy-2-fluoro-ß-hydroxy with RT: 14.416 present in Cassia fistula

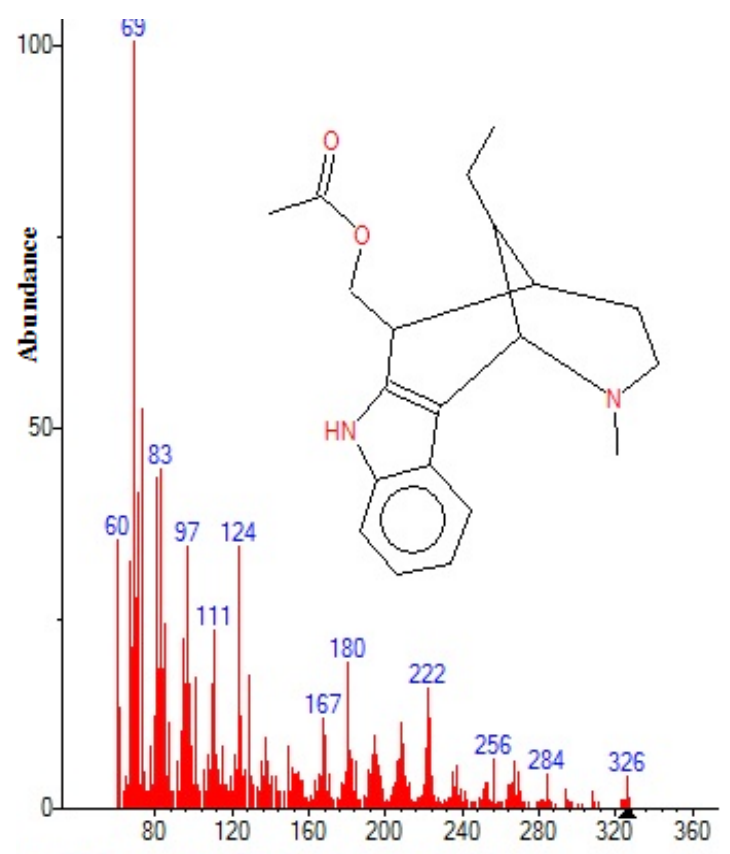

mainlib) Dasycarpidan-1-methanol, acetate (ester)

Time

Fig. 20: Structure of Dasycarpidan

-1-methanol, acetate (ester) with RT: 15.870 present in Cassia fistula

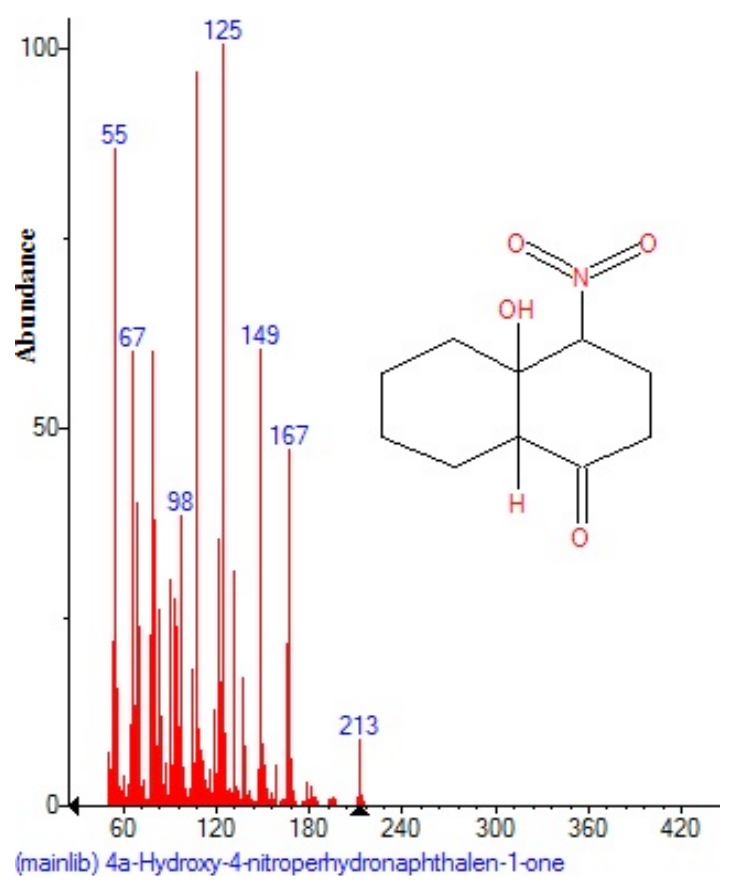

Time

Fig. 19: Structure of 4a-Hydroxy-4nitroperhydronaphthalen-1-one with RT: 15.468 present in Cassia fistula

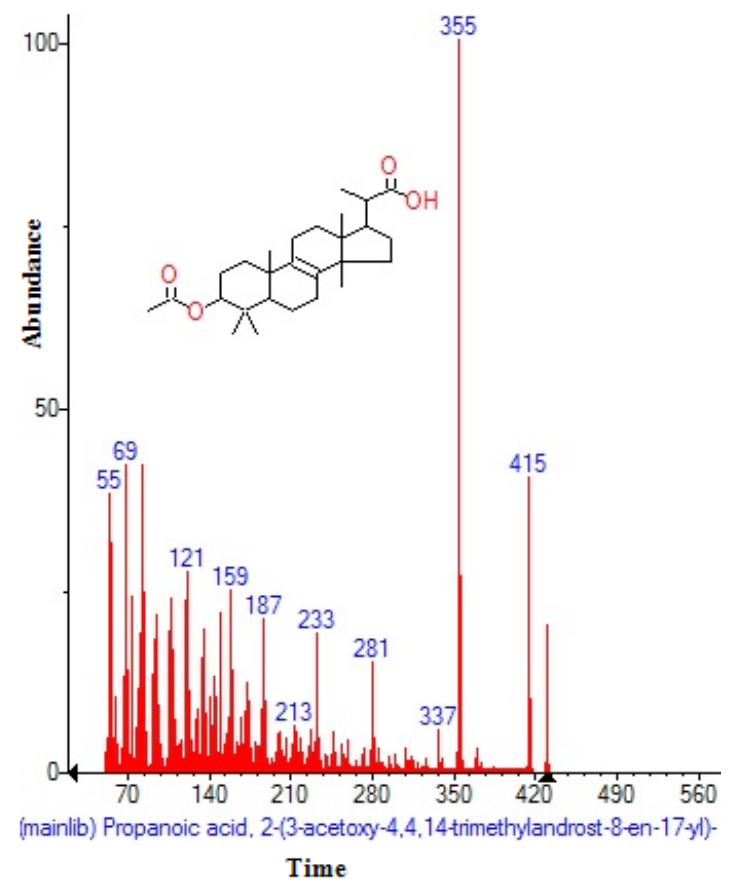

Fig. 21: Structure of Propanoic acid, 2-(3acetoxy-4,4,14-trimethylandrost-8-en-17-yl) with RT: 16.745 present in Cassia fistula 


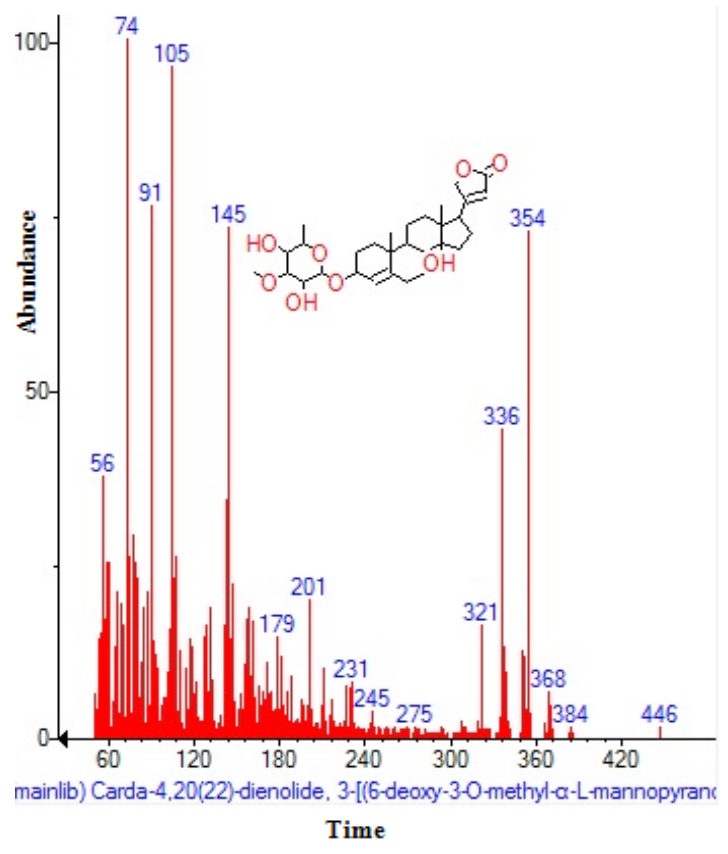

Fig. 22: Structure of Carda-4,20(22)dienolide,3-[(6-deoxy-3-0-methyl- $\alpha$-Lmannopyranosyl with RT: 18.473 present in Cassia fistula

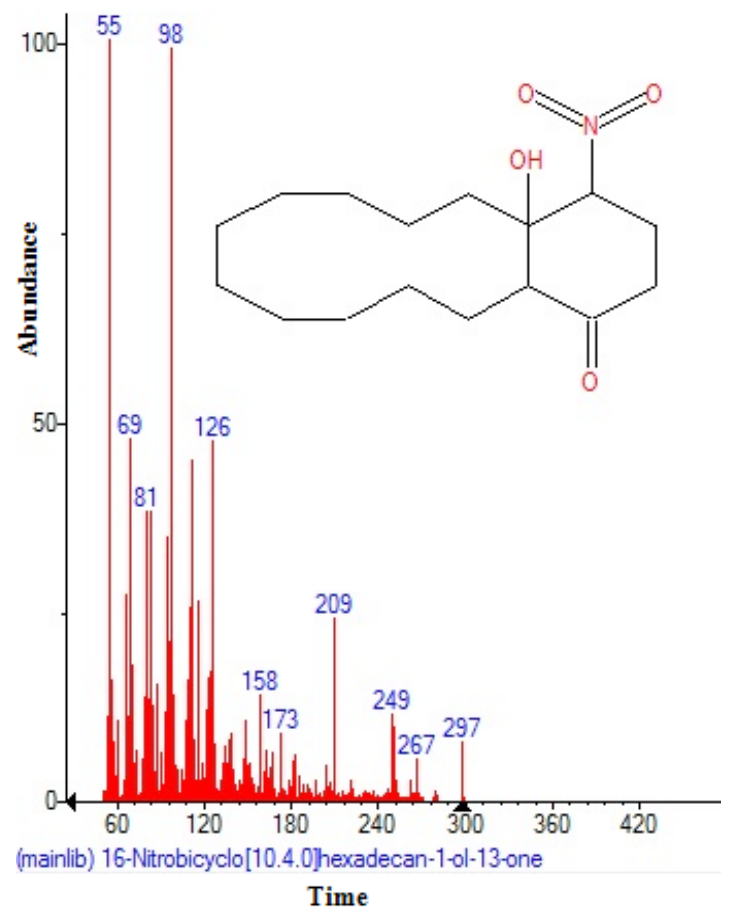

Fig. 24: Structure of 16-Nitrobicyclo[10.4.0] hexadecane-1-ol-13-one with RT: 19.080 present in Cassia fistula

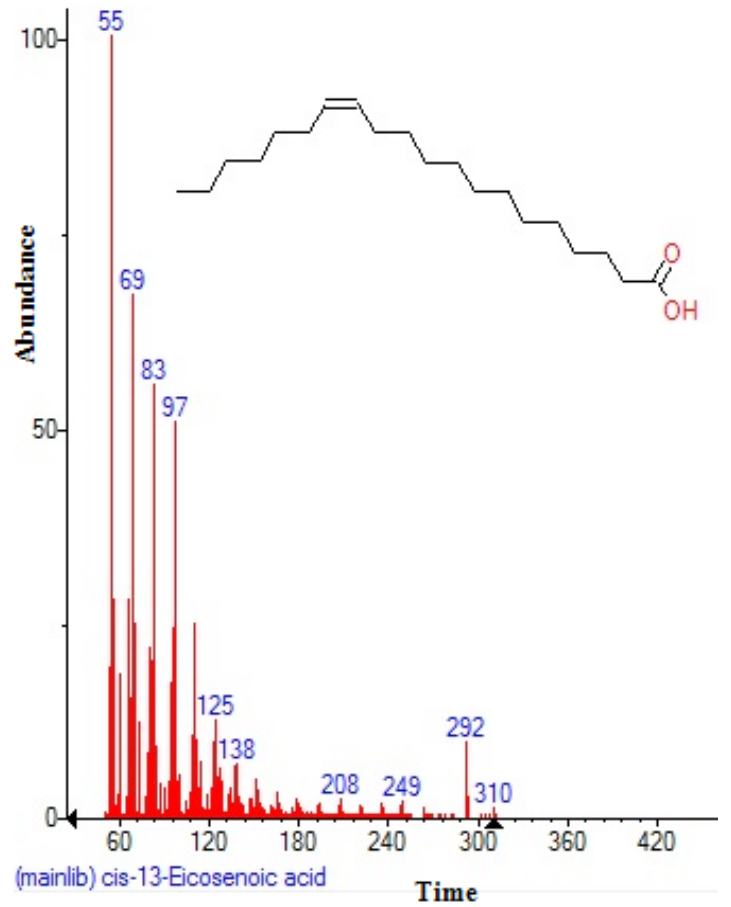

Fig. 23: Structure of Cis-13-Eicosenoic acid with RT: 18.611 present in Cassia fistula

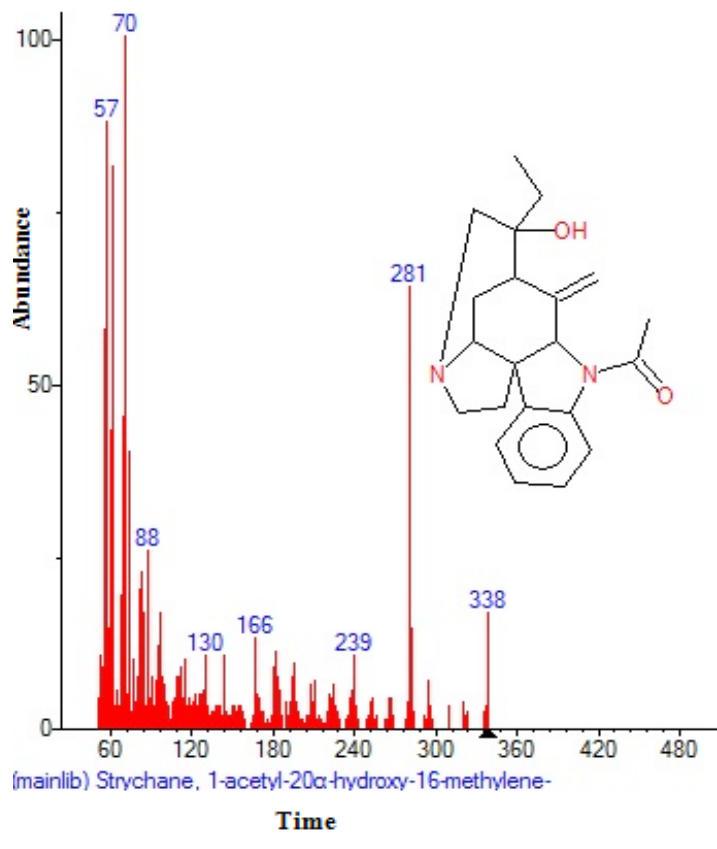

Fig. 25: Structure of Strychane ,1-acetyl-20 $\alpha$ hydroxy-16-methylene with RT: 19.846 present in Cassia fistula 


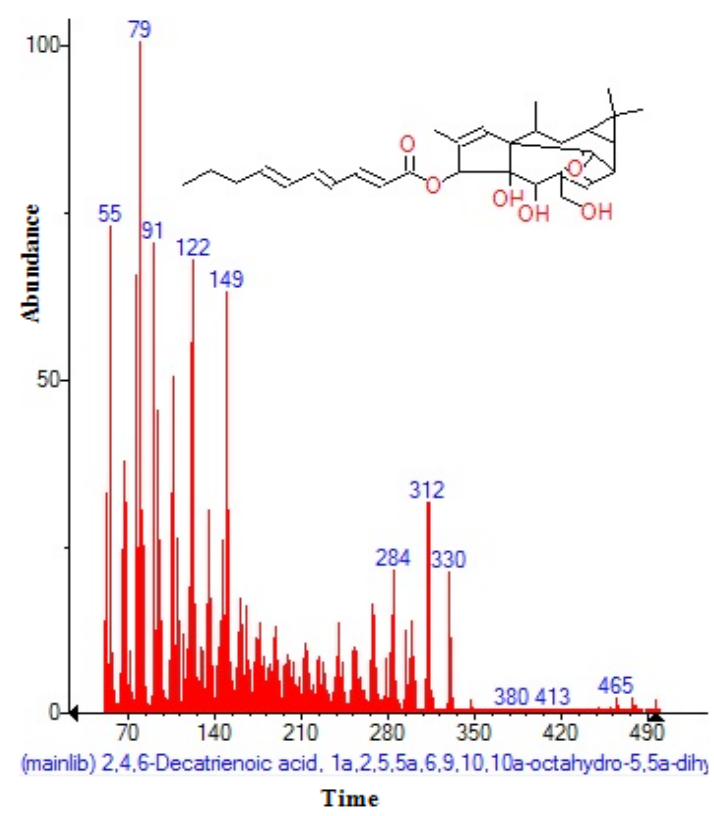

Fig. 26: Structure of 2,4,6-Decatrienoic acid , 1a,2,5,5a,6,9,10,10a-octahydro-5,5a-dihydro with RT: 21.929 present in Cassia fistula

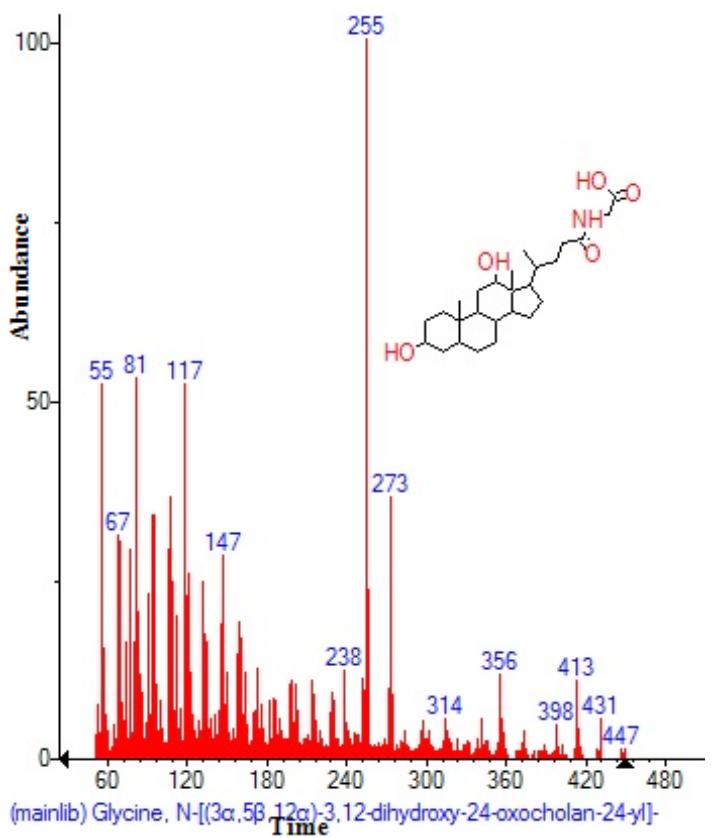

Fig. 28: Structure of Glycine , $\mathrm{N}-[(3 \alpha, 5 ß, 12 \alpha)$ 3,12-dihydroxy-24-oxocholan-24-yl] with RT: 28.893 present in Cassia fistula

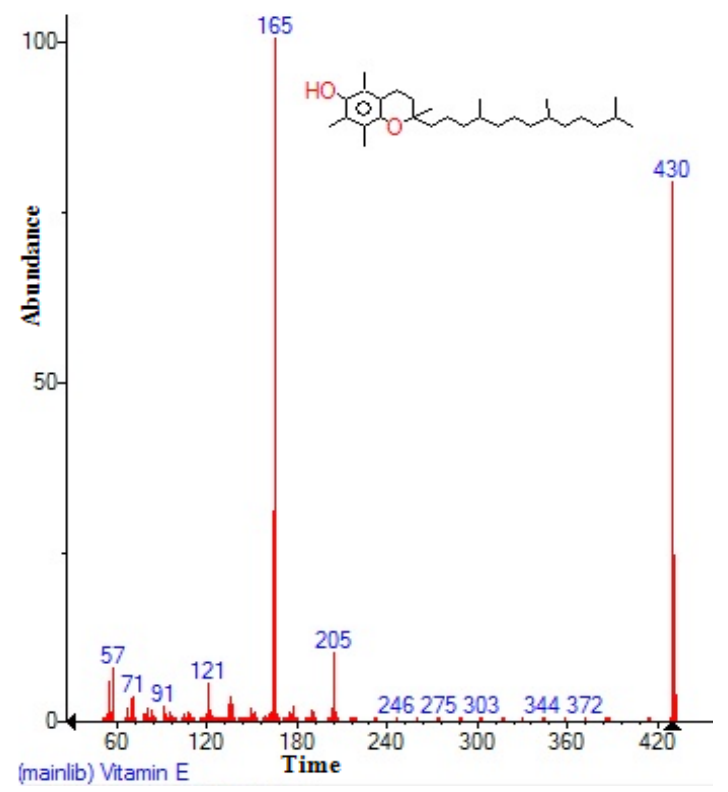

Fig. 27: Structure of Vitamin E with RT: 26.484 present in Cassia fistula

1,7-dione-6-carboxylic acid, methyl (ester), D-Glucose ,6-O-á-D-galactopyranosyl, Estragole, Phenol,2-methyl-5-(1-methylethyl), 3-Allyl-6methoxyphenol, Ppropiolic acid , 3-(1-hydroxy2-isopropyl-5-methylcyclohexyl), 7-epi-transsesquisabinene hydrate, Tetraacetyl-d-xylonic nitrile, y-Sitosterol, Ergosta-5,22-dien-3-ol, acetate , (3ß,22E), Curan-17-oic acid ,2,16-didehydro-20hydroxy-19-oxo,methyl ester, 9,10-Secocholesta -5,7,10(19)-triene-1,3-diol,25-[(trimethylsilyl) oxy], Cis-Vaccenic acid, L-Ascorbic acid, 6-octadecanoate, L-Ascorbic acid , 6-octadecanoate, Deoxyspergualin, Tributyl acetylcitrate, 10,13Dioxatricyclo[7.3.1.0(4,9)]tridecan-5-ol-2-carboxylic acid, 18,19-Secoyohimban-19-oic acid , 16,17,20,21tetradehydro-16, 9-Octadecenamide ,(Z), Olean-12ene-3,15,16,21,22,28,-hexol,(3ß,15á,16á,21ß,22á), (22S) - 21 - A ce toxy - 6á, 11 B-dihydroxy 16á,17ápropylmethylenedioxy, Ethyl isoallocholate, Olean-12-ene-3,15,16,21,22,28hexol,(3ß,15á,16á,21ß,22á) and Olean -13(18)-ene (Figure 3-28). The FTIR analysis of Cassia fistula leaves proved the presence of alkenes, aliphatic fluoro compounds, alcohols, ethers, carboxlic acids, esters, nitro compounds, hydrogen bonded 


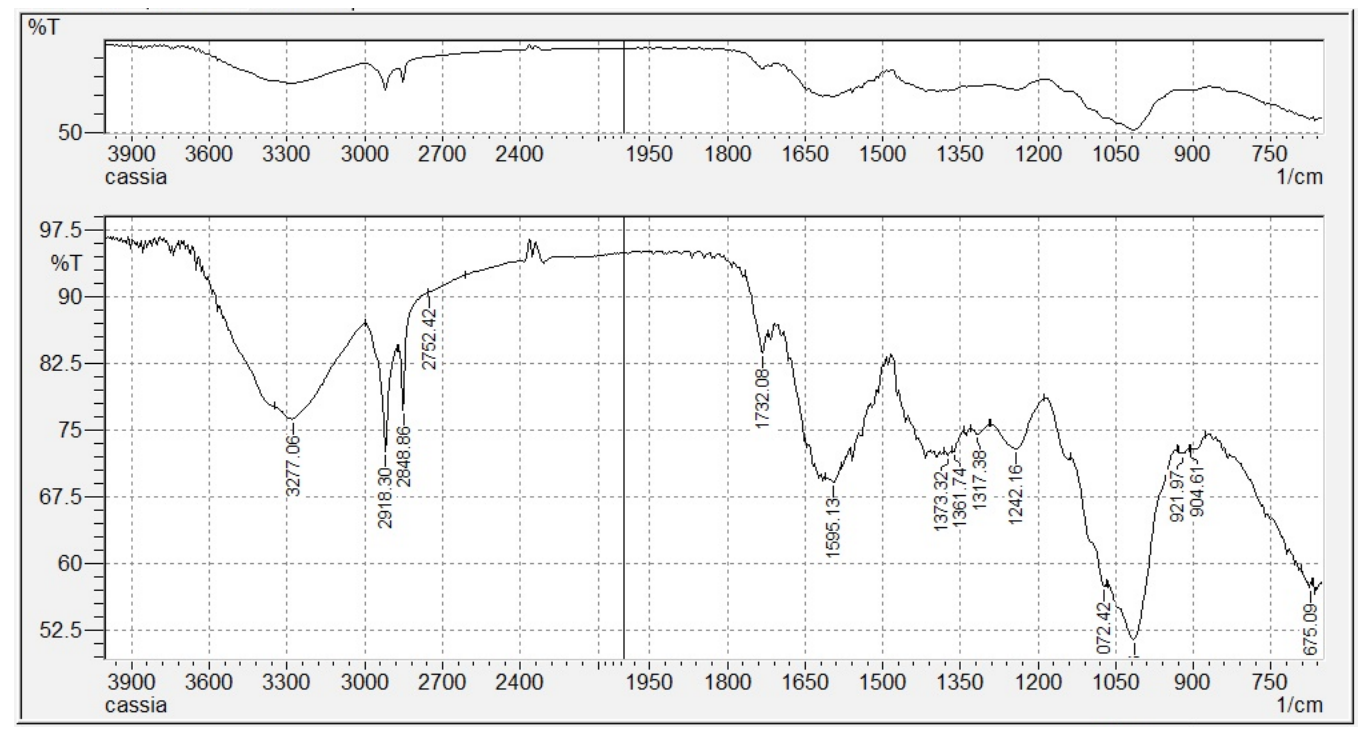

Fig. 29: FT-IR profile of Cassia fistula

alcohols and phenols which shows major peaks at $675.09,904.61,1014.56,1072.42,1242.16$, 1317.38, 1361.74, 2918.30 and 3277.06 (Table 2; Figure 29). Cassia fistula Linn. (Cassia) family Caesalpiniaceae commonly known as Amulthus has been extensively used in Ayurvedic system of medicine for various ailments ${ }^{30}$. Cassia fistula is widely used in traditional medicinal system of India has been reported to possess hepatoprotective, anti-inflammatory, antitussive, antifungal and used also check wounds healing and antibacterial ${ }^{15}$. Fruits are used as catharatic and in snake bite. Juice of leaves is used in skin diseases ${ }^{31-33}$. Flowers and pods are used as purgative, febrifugal, biliousness and astringent. The ethanolic 50\% extract of pods show antifertility activity in female albino rats. The heated pods are applied to swellings on the neck due to cold. The fruits are reported to be used for asthma. Padma, (2006) ${ }^{17}$ tested the methanolic leaf extract of Cassia fistula for activity against Candida albicans showed highest activity i.e., upto $21 \mathrm{~mm}$ which was comparable with the standard antifungal antibiotic, clotrimazole.

\section{Evaluation of antimicrobial activity}

In the current study, the anti-microbial activity of the methanolic extract was evaluated by determining the zone of inhibition against five bacteria and fourteen fungi and yeast. Clinical pathogens were selected for antibacterial activity namely, (Bacillus subtilis, Pseudomonas eurogenosa, Streptococcus faecalis, Salmonella typhi and Staphylococcus aureus. Maximum zone formation was against Streptococcus faecalis. Methanolic extraction of plant showed notable antifungal activities against Aspergillus niger, Aspergillus terreus, Aspergillus flavus, Aspergillus fumigatus, Candida albicans, Saccharomyces cerevisiae, Fusarium sp., Microsporum canis, Streptococcus faecalis, Mucor sp., Penicillium expansum, Trichoderma viride, Trichoderma horzianum and Trichophyton mentagrophytes. Cassia fistula was very highly active against Aspergillus terreus (7.09 \pm 0.32$)$. Results of antimicrobial activity are presented in Table 3 . In comparison to the antibiotics used in this study, the plants extracts were far more active against the test bacterial strains.

\section{CONCLUSION}

Medicinal property of plant extract is due to presence of secondary metabolites. Twenty seven phytoconstituents were identified from methanol extract of Cassia fistula by gas chromatogram and mass spectrometry (GC-MS) analysis. This plant derived bioactive compounds used as source of antibiotic properties and pharmaceutical industries used for drug formulation. This plant crude extract 
showed the phytochemical constituent has great potential for food resource and malnutrition of human health.

\section{ACKNOWLEDGMENTS}

Special thanks to Prof. Abdul-Kareem, Babylon University, Faculty of science for women, for his special care.

\section{REFERENCES}

1. Vashista, P.C.Taxonomy of Angiosperms.P.B.M. Press, New Delhi, India. Balunas.M.J.and A.D. Kinghorn, 2005. Drug discovery frommedicinalplants.LifeSci. 1974, 78, 431441.

2. Ogunti, E.O; Elujoba, A.A. Journal of Fitoterapia. 64 (5), 437-439.

3. Al-Marzoqi, A.H.; Hameed, I.H.; Idan, S.A. African Journal of Biotechnology. 2015, 14(40), 2812-2830.

4. Hussein, A.O.; Mohammed, G.J.; Hadi, M.Y.; Hameed, I.H. Journal of Pharmacognosy and Phytotherapy. 2016, 8(3), 49-59.

5. Mishra, N.; Behal, K.K. Int. J Pharm Sci. 2010, 2, 187-196.

6. Hussein, H.J.; Hadi, M.Y.; Hameed, I.H. 2016, 8(3), 60-89.

7. Altameme, H.J.; Hadi, M.Y.; Hameed, I.H. Journal of Pharmacognosy and Phytotherapy. 2015a, 7(10), 238-252.

8. Al-Marzoqi, A.H.; Hadi, M.Y.; Hameed, I.H. Journal of Pharmacognosy and Phytotherapy. 2016, 8(2), 25-48.

9. Hadi, M.Y.; Mohammed, G.J.; Hameed, I.H. Journal of Pharmacognosy and Phytotherapy. 2016, 8(2), 8-24.

10. Martin, J.S.; Martin, M.M., Oecologia. 1982, 54, 205-211.

11. Winnicka, K.; Bielawski, K.; Bielawski, A. Acta Poloniae Pharmaceutica, 2006, 63, 109-115.

12. PerwezHussain, S., Peijun, H.; Glewood, E. The Jour of Can Research. 2008, 68(17), 7130-6.

13. Fabricant, D.S.; Farnsworth, N.R. Environ Health Prospect. 2001; 109: 69-75.

14. Gupta, A.K.; Tondon, N.; Sharma, M. Quality Standards of Indian Medicinal Plants, Medicinal Plants Unit, Published by Indian Council of Medical Research, Vol 2, 2008, 47-53.
15. Gupta, R.K. Medicinal \& Aromatic plants, CBS publishers \& distributors, 1st edition, 2010, 116-117.

16. Kirtikar, K.R.; Basu, B.D. Indian Medicinal Plants, International book distributors, 2006, 2, 856-860.

17. Padma, S. Indian Journal of Microbiology, 2006, 46(2), 169-170.

18. Altameme, H.J.; Hameed, I.H.; Abu-Serag, N.A. Malays. Appl. Biol. 2015b, 44(4), 4758.

19. Hameed, I.H.; Abdulzahra, A.I.; Jebor, M.A.; Kqueen, C.Y.; Ommer, A.J. 2015a, 26(4), 544-9.

20. Hameed, I.H.; Hamza, L.F.; Kamal, S.A. Journal of Pharmacognosy and Phytotherapy. 2015b, 7(8), 132-163.

21. Hussein, H.M.; Hameed, I.H.; Ibraheem, O.A. International Journal of Pharmacognosy and Phytochemical Research. 2016, 8(3).

22. Altameme, H.J.; Hameed, I.H.; Idan, S.A.; Hadi, M.Y. Journal of Pharmacognosy and Phytotherapy. 2015c, 7(9), 221-237.

23. Sathyaprabha, G.; Kumaravel, S; Ruffina, D.; Praveenkumar, P.A. J Pharma Res. 2010, 3, 2970-2973.

24. Hameed, I.H.; Hussein, H.J.; Kareem, M.A.; Hamad, N.S. Journal of Pharmacognosy and Phytotherapy. 2015c, 7 (7), 107-125.

25. Hamza, L.F.; Kamal, S.A.; Hameed, I.H. Journal of Pharmacognosy and Phytotherapy. 2015, 7(9), 194-220.

26. Jasim, H.; Hussein, A.O.; Hameed, I.H.; Kareem, M.A. Journal of Pharmacognosy and Phytotherapy. 2015, 7 (4), 56-72.

27. Hameed, I.H.; Ibraheam, I.A.; Kadhim, H.J. Journal of Pharmacognosy and Phytotherapy. 2015d, 7(6), 90-106.

28. Udayaprakash, N.K.; Bhuvaneswari, S.; Jahnavi, B.; Abhinaya K.; Rajalin AG. Res J Med Plant. 2012, 6, 341-345. 
29. Pallab, M.; Dhananjay H.; Uday B.; Dipak, K.M. Indian Journal of Experimental Biology, 2009, 47, 849-861.

30. Chopra, R.N.; Nayar, S.L.; Chpora, I.C. Glossary of Indian Medicinal Plants, National Institute of Science Communication and Information Resources, 2006, page no. 54.
31. Agarwal, S.S.; Paridhavi, M. Clinically useful herbal drugs, Ahuja Publishing House, 2005, 281-282.

32. Kaur, R.; Kaur, H. Oriental Journal of Chemistry. 2015, 31(1), 597-600.

33. Chandrashekharaiah, K.S. Oriental Journal of Chemistry. 2013, 29(3), 1061-1070. 